\title{
RESPONSES OF CONCRETE VERTICAL WALLS TO TSUNAMI WAVE PRESSURES AND DEBRIS IMPACT
}

\author{
Naoto Kihara $^{1}$, Hideki Kaida ${ }^{1}$, Atsushi Shibayama ${ }^{1}$, and Yoshinori Miyagawa ${ }^{1}$
}

\begin{abstract}
By carrying out a set of experiments on the responses of vertical concrete/RC walls to tsunami impacts, the characteristics of the responses of concrete/RC walls to tsunami impacts were investigated. Experiments on both the responses of walls to only tsunami wave pressure and those to both tsunami wave pressure and debris collision were carried out. In experiments on the responses only to tsunami wave pressure, flexural failure at the base of the wall was observed when the bending moment at the base of the wall was greater than the predicted cracking moment. In experiments on the responses to both tsunami wave pressure and debris impact, flexural cracks and failure at the base of the wall were observed in some cases, and impulsive oscillations whose frequency immediately after debris collision depended on the debris material were observed.
\end{abstract}

Keywords: tsunami; debris collision; wave pressure; wall responses; large-scale experiments

\section{INTRODUCTION}

The 2011 Tohoku earthquake tsunami struck a wide area of the northeastern coast of Japan, damaging many coastal structures and buildings. To consider disaster prevention planning toward the rapid recovery of disaster-affected areas, the fragility of infrastructure against tsunami impacts is useful information. The major tsunami impacts, which have the potential to damage structures in coastal areas, are tsunami wave pressure, buoyancy, debris collision, and erosion. The fragility of infrastructure needs to be evaluated in terms of both the magnitude of tsunami impacts and the responses of structures to the tsunami impacts.

The characteristics and the quantitative evaluation methods for tsunami wave pressure and debris impact force have been extensively investigated in last two decades (e.g., Asakura et al., 2002; Arikawa et al., 2005; Ko et al., 2014). Some engineering assessment methodologies on the tsunami impacts to structures were proposed (ASCE, 2016; Naito et al., 2013, 2016; Nistor et al., 2017). However, their applicability remains unclear, because there are not enough knowledges on the responses of structures to tsunami impacts and evaluation methods on them.

The responses of structures to tsunami impacts are evaluated by methods selected by considering the design of the structures, the type of tsunami impact, and the expected damage mode. In order to select appropriate evaluation methods, the characteristics of the responses of structures to tsunami impacts and the applicability of the evaluation methods should be well understood.

In this study, to clarify the responses of concrete or reinforced concrete (RC) walls to tsunami impacts and to obtain experimental data for verifying the validity of evaluation methods, we carry out experiments on the responses of concrete/RC vertical walls to tsunami wave pressure and debris collision.

\section{EXPERIMENTS}

Experiments on both the responses of walls to only tsunami wave pressure and those to both tsunami wave pressure and debris collision were carried out (Figure 1). Since details of the experiments are given in Kaida et al. (2014) and Shibayama et al. (2018), a brief description is given here. The Large-Scale Tsunami Physical Simulator in Central Research Institute of Electric Power Industry (Kihara, 2016) was used for the experiments (Figure 2). The experimental flume consist of a storage tank with a length of $14.4 \mathrm{~m}$ and a test section that is an open channel with a length of $20 \mathrm{~m}$, a height of $2.5 \mathrm{~m}$ high, and a width of $4 \mathrm{~m}$. There is a radial gate between the storage tank and the test section. Tsunami-like bores were generated by rapidly opening the radial gate.

A vertical wall, whose width is $1 \mathrm{~m}$ and height is $1.5 \mathrm{~m}$, was installed on the flat bed in the test section. The wall has a reversed T-shape. Four types of vertical walls were used. The first, second, and third walls were concrete walls with the thicknesses of $0.05,0.1$, and $0.15 \mathrm{~m}$, denoted as N50, N100, and $\mathrm{N} 150$, respectively. The fourth wall was an RC wall of 0.1 m thickness, denoted as RC100. In the experiments on the responses of walls to both tsunami wave pressure and debris collision, a debris model was initially set on the flat bed $7.6 \mathrm{~m}$ upstream from the vertical wall. Two types of column-shaped debris with a mass of $48 \mathrm{~kg}$ were used. The surface material of the first type of debris was polyethylene foam and that of the second type of debris was steel.

\footnotetext{
${ }^{1}$ Nuclear Risk Research Center, Central Research Institute of Electric Power Industry, 1646 Abiko, Abiko-shi, Chiba, 270-1197, Japan
} 
Three different tsunami-like bores were used in the experiment, for which the initial water depths in the storage tank and test section were different (Table 1).

Before the experiments on the responses of walls, flow-measuring experiments were carried out. In the experiments, the water depths and velocities were measured without the vertical wall. The water depths were measured by ultrasonic level sensors (Omron Co., Ltd., E4PA-LS400) installed $3.0 \mathrm{~m}$ above the flume bottom at points H1, H2, and H3 in Figure 2 (b). The velocities were measured at a height of $0.1 \mathrm{~m}$ from the bed at point $\mathrm{V} 1$ by a two-component $(x, z)$ electromagnetic velocimetry. In the experiments on the responses to only tsunami wave pressure, the water depths, pressures on the wall, and strains of the wall were measured. The pressures were measured at 23 points along a centerline on the upstream face of the vertical wall. Pressure transducers (SSK Co., Ltd., P310) with an upper pressure limit of $49 \mathrm{kPa}$ were aligned in the vertical direction at heights of $z=0.01,0.05,0.1,0.15,0.2,0.25,0.3$, $0.31,0.35,0.4,0.45,0.5,0.55,0.6,0.7,0.8,0.9,1.0,1.1,1.2,1.3,1.4$, and $1.49 \mathrm{~m}$. In the experiments with concrete walls, the surface strains of the walls were measured, and in the experiments with RC walls, the reinforcement strains were additionally measured. The heights of the strain-measurement points varied among the experiments. In the experiments on the response to both the tsunami wave pressure and debris collision, the water depths, strains of the wall, and the acceleration of the debris were measured. The data were recorded by a data logger (Kyowa Electronic Instruments Co., Lt.d, EDX-3000A) at a sampling rate of $10 \mathrm{kHz}$. The experimental conditions are summarized in Table 2.

\begin{tabular}{|c|c|c|c|}
\hline \multicolumn{4}{|c|}{ Table 1. Flow conditions. } \\
\hline Flow type & $\begin{array}{l}\text { Initial water depth in test } \\
\text { section [m] }\end{array}$ & $\begin{array}{l}\text { Initial water depth in } \\
\text { storage tank [m] }\end{array}$ & $\begin{array}{l}\text { Maximum bending moment } \\
\text { at base of wall [kNm] }\end{array}$ \\
\hline Type 1 & 0 & 1.3 & 1.3 \\
\hline Type 2 & 0 & 1.7 & 2.0 \\
\hline Type 3 & 0.3 & 2.0 & 5.2 \\
\hline
\end{tabular}

\begin{tabular}{|c|c|c|c|}
\hline Wall tyne & Flow type & Debris tyne & Damage of wall \\
\hline \multirow{2}{*}{ N50 } & Type 1 & None & None \\
\hline & Type 2 & None & Collapse \\
\hline \multirow{3}{*}{ N100 } & \multirow{3}{*}{ Type 3} & None & None \\
\hline & & Polyethylene & None \\
\hline & & Steel & Collapse \\
\hline \multirow{3}{*}{ N150 } & \multirow{3}{*}{ Type 3} & None & None \\
\hline & & Polyethylene & None \\
\hline & & Steel & Crack \\
\hline \multirow{3}{*}{ RC100 } & \multirow{3}{*}{ Type 3} & None & None \\
\hline & & Polyethylene & None \\
\hline & & Steel & Crack \\
\hline
\end{tabular}

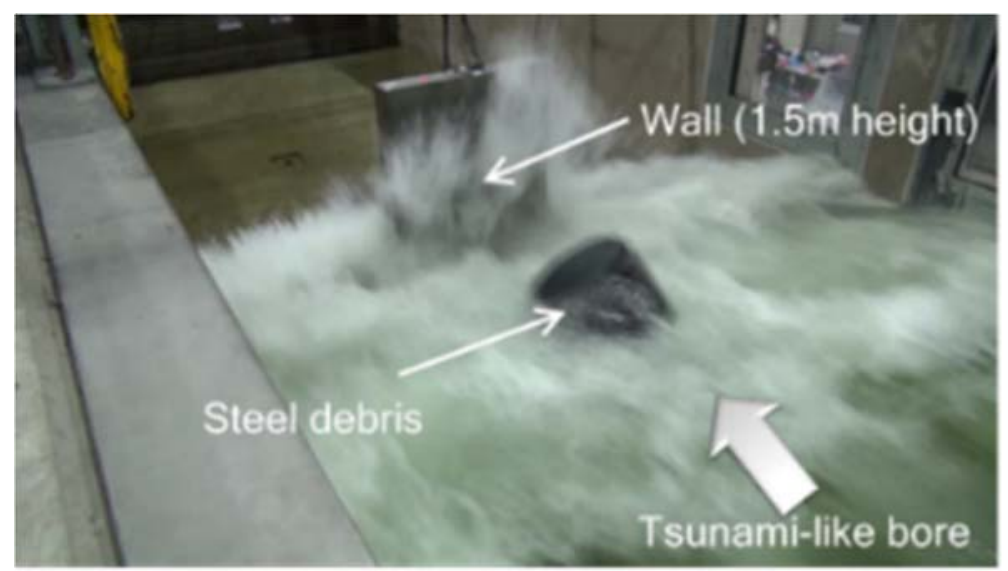

Figure 1. A photograph of the experiment on the response to both tsunami wave pressure and debris collision. 


\section{EXPERIMENTAL RESULTS}

\section{Flow profiles and pressures}

The time series of water depths and velocities in the streamwise direction measured at H2 and V1 ( $x$ $=-5.4 \mathrm{~m}$ ) for flow types 1, 2, and 3 are shown in Figure 3. The Froude number estimated from the water depth at $\mathrm{H} 2$ and the velocity in the streamwise direction at V1, and the bending moment at the base of the wall, estimated from the pressure distribution on the wall, are also shown in Figure 3. For the flow types with an initially dry bed (types 1 and 2), the maximum velocity was observed immediately after the bore passed the measurement points. The maximum Froude number was approximately 3 . On the other hand, for the flow type with an initially wet bed (type 3), the maximum water depth was greater than those for types 1 and 2, but the maximum velocity was lower than those for types 1 and 2 . The largest bending moment at the base of the wall was observed for type 3 and the smallest was for type 1 . For type 3, a high bending moment was observed during the high-velocity regime.

The vertical distributions of the pressure at the front face of the wall at the times of the first, second, and third peaks of the bending moment for flow type 3 are shown in Figure 4 . At the first peak, the pressure was not hydrostatically distributed. The distribution was the typical form observed immediately after a bore impacts on a wall, which was previously reported early studies (e.g., Kihara et al. 2015). The vertical distribution of the pressure approached a hydrostatic distribution at the second and third peaks.

(a)

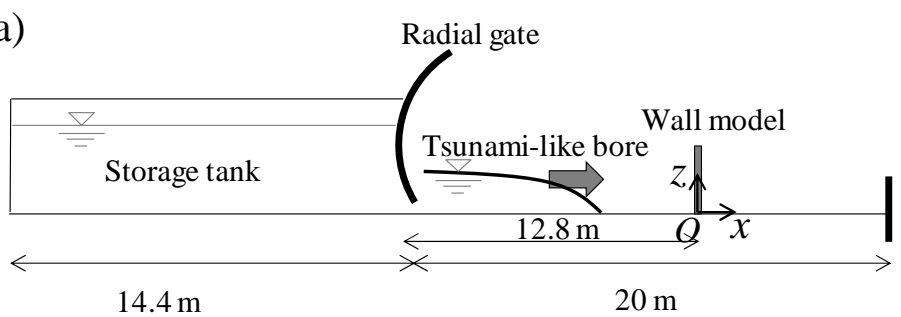

(b)

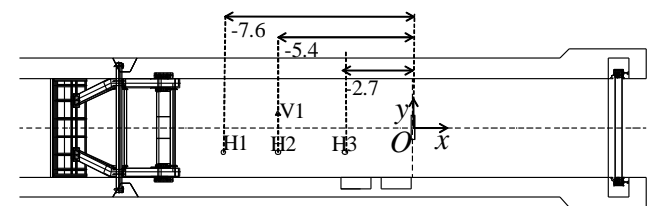

Figure 2. Schematic view of the experimental flume.
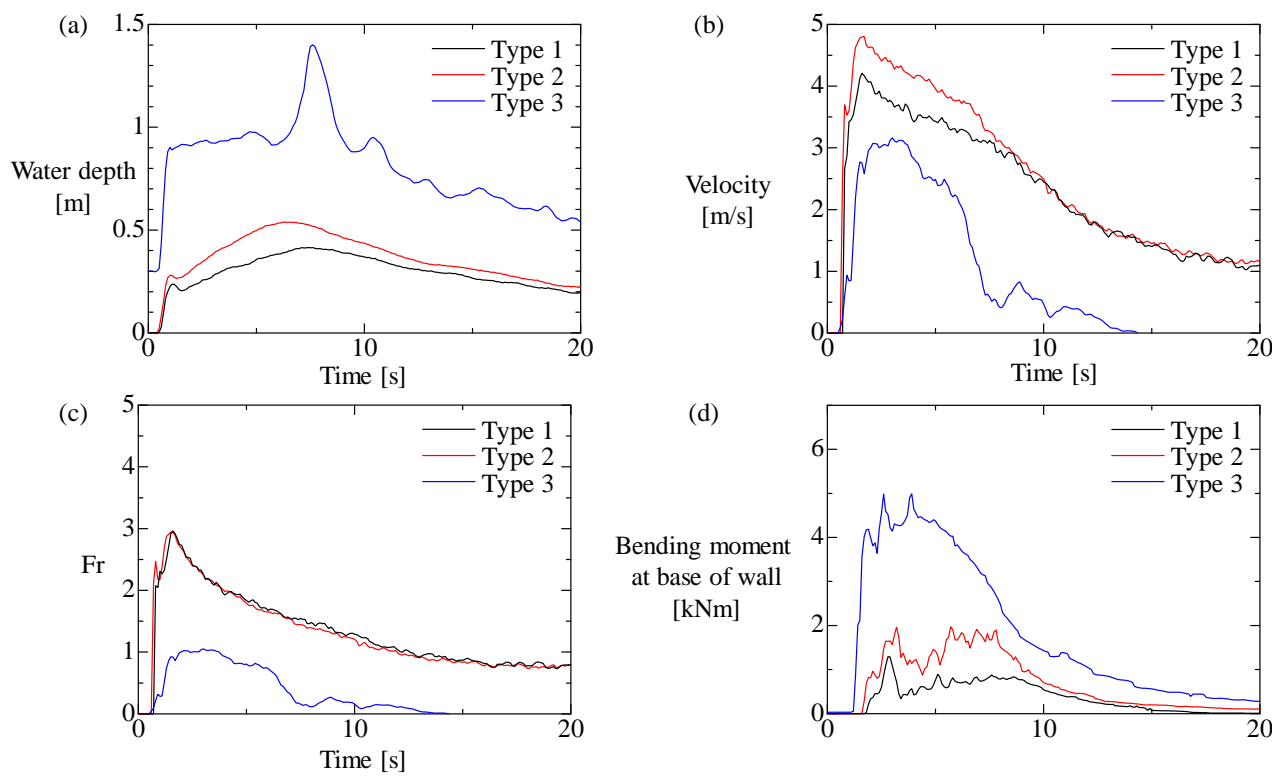

Figure 3. Time series of water depths and velocities measured at $\mathrm{H} 2$ and V1. The estimated Froude number and bending moment at the base of the wall are also shown. 


\section{Response of N50 wall to wave pressure}

In the experiments on the response to only the tsunami wave pressure for wall N50, flow types 1 and 2 were used. Although the wall was not damaged for flow type 1, it collapsed for flow type 2. The cracking moment $M_{c r}$ can be predicted using

$$
M_{c r}=f_{t} Z \text {, }
$$

where $f_{t}$ is the bending strength of concrete $\left(\mathrm{N} / \mathrm{mm}^{2}\right)$, and $Z$ is the cross-sectional coefficient $\left(\mathrm{mm}^{3}\right)$. The predicted cracking moment $M_{c r}$ for N50 was $1.5 \mathrm{kNm}$. The maximum bending moments were 1.3 and $2.0 \mathrm{kNm}$ for flow types 1 and 2, respectively. Thus, the experimental results show that the capacity of flexural failure at the base of the wall due to tsunami wave pressure can be predicted from the cracking moment.

\section{Responses of N100, N150, and RC100 walls to wave pressure}

Experiments on the responses of the N100, N150, and RC100 walls were carried out for flow type 3. Time series of the compressive strains in the experiment on the response to only tsunami wave pressure for the N100, N150, and RC100 walls are shown in Figure 5 (a). The compressive strains were measured on the downstream face of the wall at a height of $180 \mathrm{~mm}$. In Figure 5 (b), the vertical distributions of the maximum compressive strains are also shown. The vertical distribution shows that the surface compressive strains measured near the base of the walls were larger than those measured at the other heights. A comparison between the time series of the compressive strain (Figure 5 (a)) and the bending moment (Figure $3(\mathrm{~d})$ ) shows that the compressive strains strongly correlated with the bending moment at the base of the wall to tsunami wave pressure. Under the same flow conditions, the magnitude of the surface compressive strains of N100 was larger and that of N150 was smaller than that of RC100, except at the smallest height.

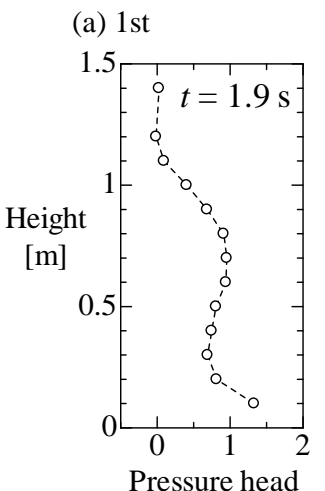

$[\mathrm{m}]$ (b) 2nd

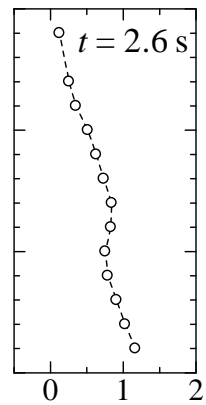

Pressure head

$[\mathrm{m}]$ (c) 3rd

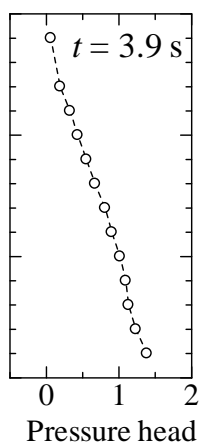

[m]

Figure 4. Vertical distributions of pressure measured at first, second, and third peaks of the bending moment at the base of the wall for flow type 3.
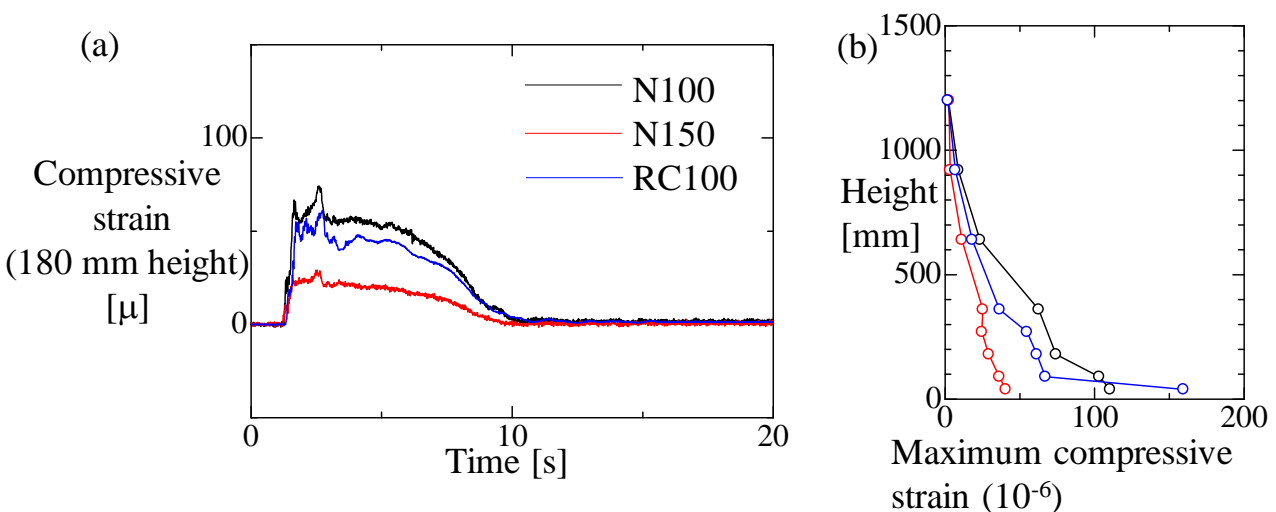

Figure 5. (a) Time series of the compressive strains at a height of $180 \mathrm{~mm}$ in the experiment on the response to only tsunami wave pressure for the N100, N150, and RC100 walls. (b) Vertical distributions of maximum compressive strains for the N100, N150, and RC100 walls. 


\section{Responses of N100, N150, and RC100 walls to both wave pressure and debris collision}

In the experiments on the responses to both the tsunami wave pressure and debris collision, flow type 3 was used for the N100, N150, and RC100 walls. Two types of debris were used. From the videos of the experiments, the approach speeds of the debris $1 \mathrm{~m}$ upstream from the wall were approximately 3 $\mathrm{m} / \mathrm{s}$, which is almost equal to the flow velocity. However, the speeds of the debris rapidly decreased near the wall, and the collision speeds ranged from $0.5 \mathrm{~m} / \mathrm{s}$ to $2 \mathrm{~m} / \mathrm{s}$. Unfortunately, the correct collision speed could not be measured because the video installed $2.5 \mathrm{~m}$ above the bed was not able to capture the motion of the debris due to high splashes immediately in front of the wall.

After the collision of the debris with the polyethylene foam, no damage to the walls was observed. Time series of the compressive strains in cases of polyethylene foam debris collision are shown in Figure 6. The compressive strains were measured at the downstream face of the wall at a height of $180 \mathrm{~mm}$. Compared with those in the experiment on the response only to the tsunami wave pressure (Figure 5 (a)), similar time-series distributions were observed, except for impulsive oscillations with a fundamental mode of $15 \mathrm{~Hz}$ immediately after the debris collision.

On the other hand, after the collision with the steel debris, damage to the walls was observed. For N100, flexural failure at the base of the wall was observed and the wall collapsed. For N150 and RC100, flexural cracks at the bases were observed, but the walls did not collapse. Compared with polyethylene debris, steel debris has much large stiffness. Thus, even if the collision speed was same, the collision force would be much larger, and the impact period would be much shorter, as early studies showed (e.g., Haehnel and Daly, 2004). The compressive strains for N100 could not be measured because of its flexural failure immediately after debris collision. Thus, the time series distributions of the surface compressive strains for several heights are only shown for RC100 in the case of steel debris are shown in Figure 7. Impulsive oscillations with the fundamental mode were observed from Figure 7 (b). By examining the time series immediately after the debris collision in detail, reverse phases of oscillation with a frequency of $300 \mathrm{~Hz}$ between the strain at $z=0.09 \mathrm{~m}$ and $z=0.64 \mathrm{~m}$ were observed. Thus, higher-mode oscillation occurred immediately after the debris impact, then the frequency of the oscillation approached the natural frequency of the wall. Time series distributions of the tensile strains of the reinforcement for RC100 at several heights in the case of steel debris are shown in Figure 8. Because of residual displacement, the tensile strains at $z=0 \mathrm{~m}$ did not recover after unloading. Similarly to that observed in the characteristics in Figure 7, higher-mode oscillation occurred immediately after the debris impact, then the frequency of oscillation approached the natural frequency of the wall.

\section{Conclusions}

By carrying out a set of experiments on the responses of concrete/RC vertical walls to tsunami impacts, the characteristics of the responses of concrete and RC walls to tsunami impacts were investigated. Experiments on both the responses of walls to only tsunami wave pressure and those to both tsunami wave pressure and debris collision were carried out. The major characteristics of the responses of the walls to tsunami impacts are summarized as follows.

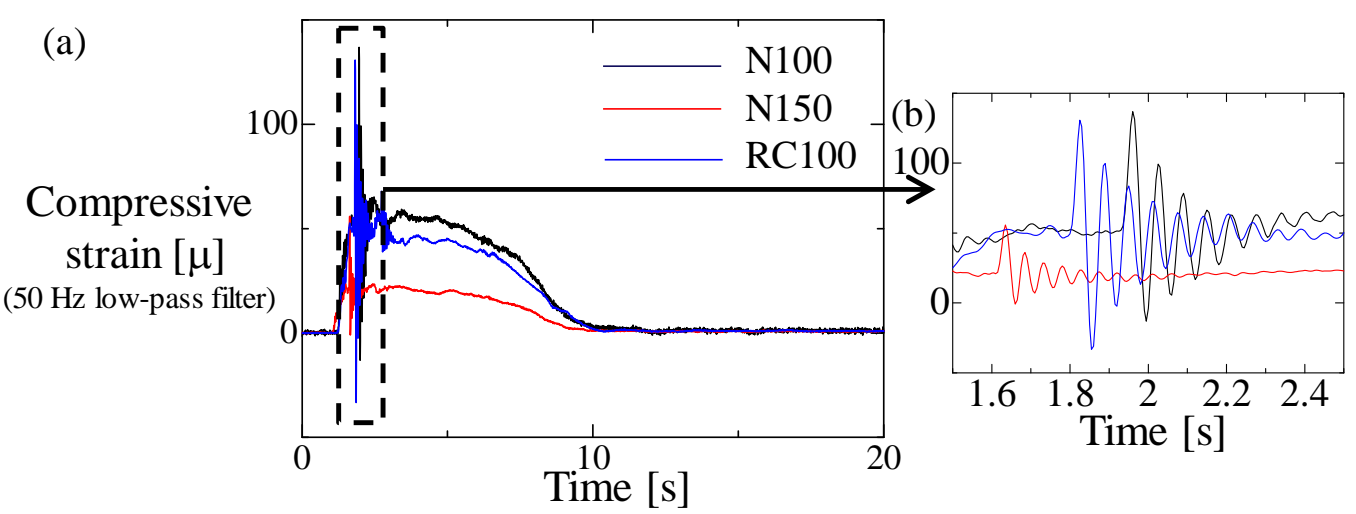

Figure 6. Time series of the compressive strains at a height of $180 \mathrm{~mm}$ in the experiment on the response to both the tsunami wave pressure and debris collision for the N100, N150, and RC100 walls. 


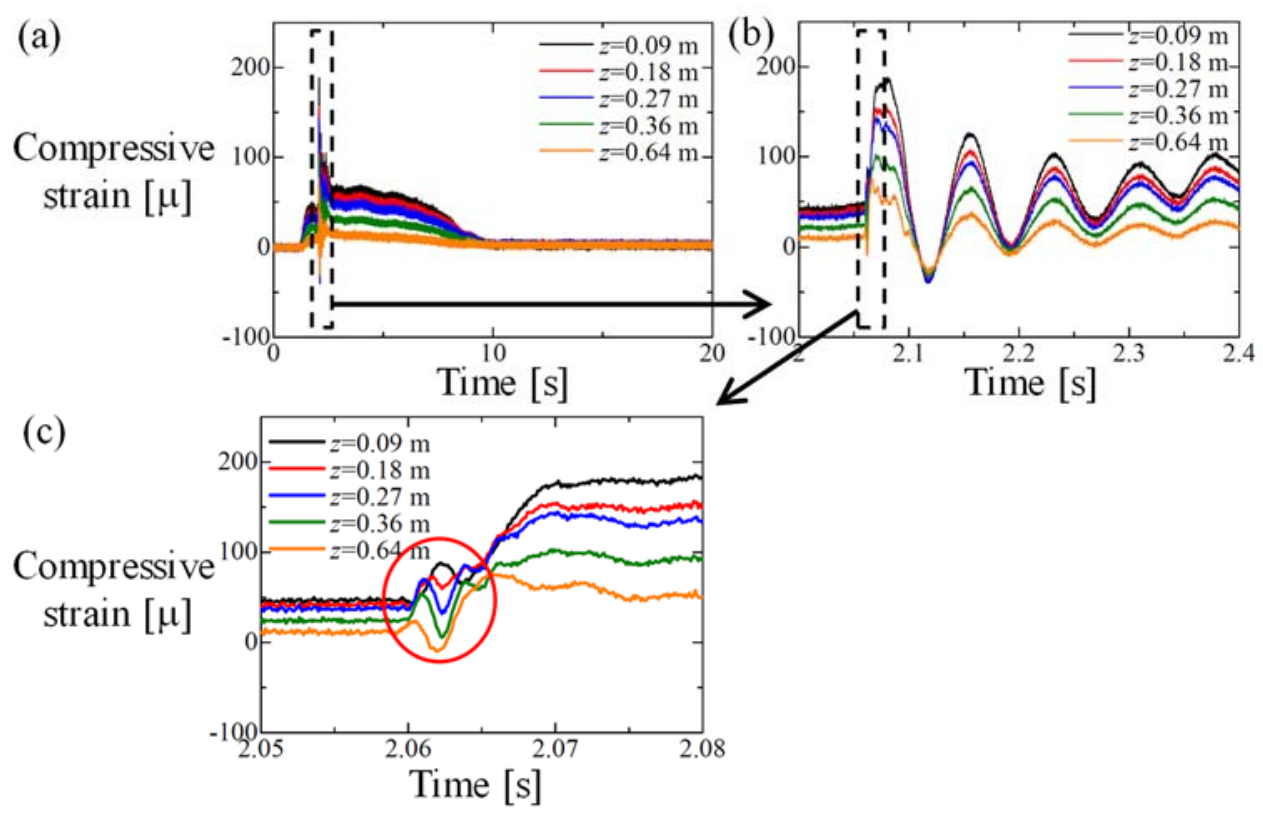

Figure 7. Time series distributions of the surface compressive strains for RC100 at several heights in the experiment on the response to both the tsunami wave pressure and steel debris collision.
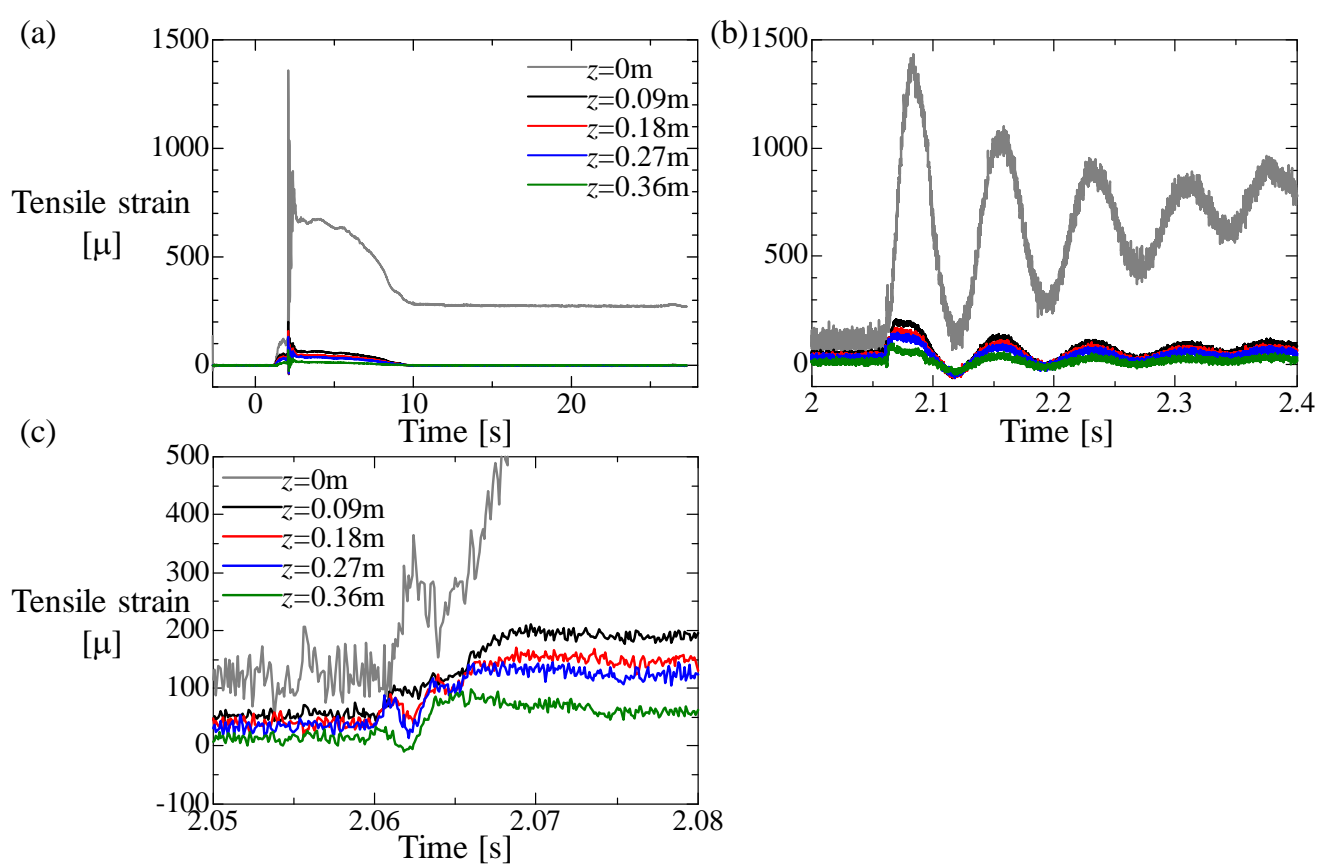

Figure 8. Time series distributions of the tensile strains of reinforcement of $R C 100$ at $x=-0.03 \mathrm{~m}$ for several heights in the experiment of the response to both the tsunami wave pressure and steel debris collision.

(1) In the cases of the response only to tsunami wave pressure, flexural failure at the base of the wall was observed when the bending moment at the base of the wall was greater than the predicted cracking moment.

(2) In the case of the response to both tsunami wave pressure and debris impact, flexural cracks and failure at the base of wall was observed in some cases, and impulsive oscillations whose frequency immediately after the debris collision was dependent on the material or stiffness of the debris were observed.

The obtained experimental data will be useful for verifying the validity of numerical models of wall responses to tsunami impacts. 


\section{REFERENCES}

Asakura, R., K. Iwase, T. Ikeya, M. Takao, T. Kaneto, N. Fujii, and M. Ohmori. 2002. The tsunami wave force acting on land structures, Proceedings of $28^{\text {th }}$ International Conference on Coastal Engineering, ASCE, 1191-1202.

ASCE. 2016. ASCE 7-16: Minimum design loads and associated criteria for buildings and other structures, ASCE.

Arikawa, T., M. Ikebe, F. Yamada, K. Shimosako, and F. Imamura. 2005. Large model test of tsunami force on a revetment and on a land structure, Annual Journal of Coastal Engineering, JSCE, 52, 746-750.

Haehnel, R.B., and S.F. Daly. 2004. Maximum impact force of woody debris on floodplain structures, Journal of Hydraulic Engineering, 130(2), 112-120.

Kaida, H., N. Kihara, A. Shibayama, D. Takabatake, Y. Miyagawa, and M. Ikeno. 2014. Large-scale experiments on development of fragility assessment method against tsunami wave force and debris impact force in tsunami PRA, Proceedings of the Japan Conference on Structural Safety and Reliability, JCOSSAR 2015. (in Japanese)

Kihara, N., Y. Niida, D. Takabatake, H. Kaida, A. Shibayama, and Y. Miyagawa. 2015. Large-scale experiments on tsunami-induced pressure on a vertical tide wall, Coastal Engineering, 99, 46-63.

Kihara, N. 2016. large-scale tsunami physical simulator: a new type of experimental flume for research on tsunami impact, Hydrolink, 1, 24-25.

Ko, H.S., D.T. Cox, H.R. Riggs, and C.J. Naito. 2014. Hydraulic experiments on impact forces from tsunami-driven debris, Journal of Waterway, Port, Coastal, and Ocean Engineering, 141(3), 04014043.

Naito, C., C. Cercone, H.R. Riggs, and D. Cox. 2013. Procedure for site assessment of the potential for tsunami debris impact, Journal of Waterway, Port, Coastal, and Ocean Engineering, 140(2), 223232.

Naito, C., H.R. Riggs, Y. Wei, and C. Cercone. 2016. Shipping-container impact assessment for tsunamis, Journal of Waterway, Port, Coastal, and Ocean Engineering, 142(5), 05016003.

Nistor, I., N. Goseberg, and J. Stolle. 2017. Tsunami-driven debris motion and loads: A critical review, Frontiers in Built Environment, 3, 2.

Shibayama A., Y. Miyagawa, N. Kihara, and H. Kaida. 2018. Response characteristics and nonlinear finite element analysis of RC walls subjected to tsunami wave pressure and driftage collision force, International Journal of Offshore and Polar Engineering (accepted) 